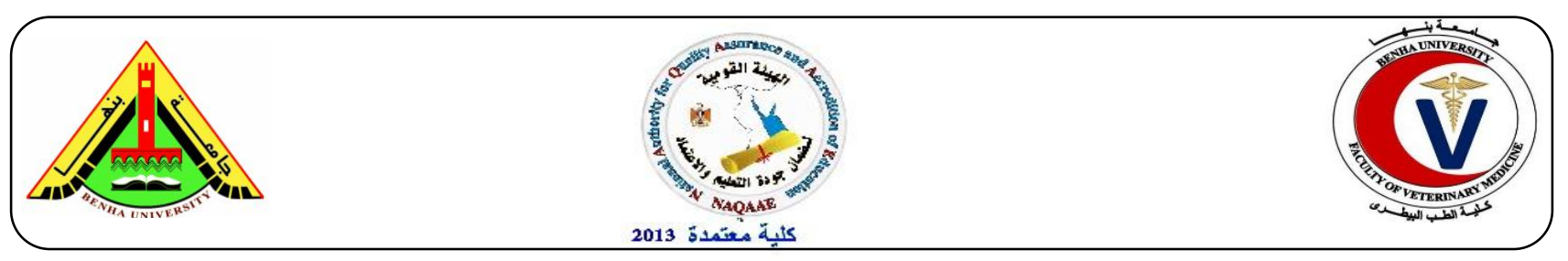

\title{
Biochemical study on the potential therapeutic use of novel curcumin copper oxide nanocomposite in diabetic complications in rats
}

Yakout A. Al-Senosy ${ }^{1}$, Abd El-Bary M. Prince ${ }^{2}$, Amira M. Abd El Zaher ${ }^{1}$

${ }^{1}$ Department of Biochemistry, Faculty of Veterinary Medicine, Benha University

${ }^{2}$ Department of Biochemistry, Faculty of Veterinary Medicine, Cairo University

\section{A B S T R A C T}

The aim of this study was to investigate the hypoglycemic and antioxidant effect of Curcumin Copper Oxide nano-composite in STZ- induced diabetic rats. Sixty male rats were divided into four equal groups. Group 1 (control) comprised 15 rats received no drugs, Group 2 (Diabetic nontreated group) included 15 rats received no drugs, serve as STZ induced diabetic group. Group 3 (Diabetic nano-curcumin treated group) consists of 15 rats, received curcumin nanoparticle orally at a dose level of $2 \mathrm{mg} / \mathrm{kg}$ b.wt/day. Group 4 (Diabetic Curcumin Copper Oxide Nano-Composite treated group): included 15 rats, received curcumin Copper Oxide Nano-Composite at a dose level of $7 \mathrm{mg} / \mathrm{kg}$ b.wt/day orally. The obtained results revealed that, diabetic rats showed significant increase in serum glucose and Malondialehyde (MDA) concentrations. However, serum Superoxide dismutase (SOD) activity, Reduced Glutathione (GSH) and insulin concentration in pancreatic tissue were markedly decreased. Moreover, a significant down regulation in Insulin Receptor-A (IRA) and Insulin Receptors Substrate-2 (IRs-2) mRNA gene levels in hepatic tissue were observed in diabetic rats. Administration of Curcumin Copper Oxide Nano-Composite in diabetic rats caused significant improvement of all previous parameters. These results suggested that, Curcumin Copper Oxide Nano-Composite treatment may decrease the diabetic complications as hyperglycemia and oxidative stress in rats through free radical scavenging as well as regulation of endogenous antioxidant defense system mechanisms.

Keywords: Diabetes mellitus, STZ- induced diabetes, Curcumin Copper Oxide Nano-Composite, oxidative stress.

(http://www.bvmi.bu.edu.eg)

(BVMJ-34(2): 182-190, 2018)

\section{INTRODUCTION}

Diabetes is a metabolic syndrome that leads to hyperglycemia and hindrance in proper metabolism of carbohydrate, protein and fat in the body resulting in poor insulin profile (Piyasi et al., 2017). Diabetes requires continuous medical care with multi factorial risk-reduction strategies beyond glycemic control. Ongoing patient self-management education and support are critical to preventing acute complications and reducing the risk of long-term complications (ADA, 2018). An optimum control of blood sugar along with prevention of several diabetic complications is essential for proper prognosis and improved life quality of the diabetics (Piyasi et al., 2017). 
Oxidative stress is suggested to be a potential contributor pathogenesis of diabetes as well as diabetic complications which have been extensively studied for years in animal models and in patients (Coskun et al., 2005). $\beta$-Diketones, a versatile ligand system, have been known to form complexes with almost every metal ion and metalloid. Curcumin, is the naturally occurring coloring pigment of Curcuma longa, is well known as an antioxidant, food additive and therapeutic agents for various diseases, and has a diketone moiety with a highly conjugated side chain. Curcumin has crucial features of a neuroprotective drug since it acts as a powerful scavenger of superoxide anions so it has both neuroprotective and antiaging effects (Joseph and Janaki, 2014).

Moreover, copper is an important biometal which is essential for normal human metabolism and its imbalance leads to deficiency or excess diseases. $\mathrm{Cu}$ (II) complexes are preferred candidates for various pharmacological studies due to the presence of its biorelevent ligands (El-Sherif, 2012). These complexes have multiple roles in medicinal proceedings such as antimicrobial, antiviral, anti-inflammatory, antitumor agents, enzyme inhibitors, or chemical nucleases with reduced side effects and it has distinct superoxide- dismutase(SOD-) mimetic activity (Tisato et al., 2010). Furthermore, metal oxide nanoparticle stress elicitors such as zinc oxide $(\mathrm{ZnO})$ and copper oxide $(\mathrm{CuO})$ have gained enormous importance in recent years (Javed et al., 2017). Accordingly, the present study was designed to evaluate the effect of Curcumin Copper Oxide nanocomposite on diabetic complications in STZ- induced diabetic rats.

\section{Materials and methods}

\subsection{Experimental animals:}

Sixty white male albino rats, 4-8 weeks old and average b.wt. $160 \pm 20$ g. was used for the experimental investigation in this study. Rats were obtained from Laboratory Animal Research Center, Faculty of Veterinary Medicine, Benha University, Egypt. Animals were housed in separate metal cages; fresh and clean drinking water was supplied adlibitum through specific nipple. Rats were kept at constant environmental and nutritional conditions during the course of the experiment. Cleaning and changing water and food was done for all animals twice daily. All animals were acclimatized for minimum period of one week prior to the beginning of study.

\subsection{Chemicals and natural drugs:}

Curcumin Nanoparticles:

Curcumin purchased from the druggist in the form of powder, then transformed to Curcumin Nanoparticles by grinding the powder for 8 hours at $400 \mathrm{rpm}$ to very small particles (Nano size) through the ball mill.

Copper Oxide Nanoparticles (CuO NPs):

Copper Oxide Nanoparticles obtained from Sigma Chemical co., the average nanoparticle size is $50 \mathrm{~nm}$, Surface Area $29 \mathrm{~m} 2 / \mathrm{g}$, and the Appearance (color) Black.

Curcumin Copper Oxide Complex:

Curcumin Nanoparticles and Copper Oxide Nanoparticles were grinded together in the ball mill to make novel Curcumin Copper Oxide Nano Composite that founded in the Nanotechnology Center _ ball mill lab by the ratio of $1: 2$.

\section{Diabetes Induction:}

Rats were fasted for 18 hours and allowed free access of water. Fasting prior to STZ injection is required in order to reduce the blood glucose level of the animals to a level that circulating glucose dose not out-compete STZ for GLUT-2 binding and transport into $\beta$-cell. The experimental induction of diabetes in male rats was induced by a single 
intraperitoneal (i.p) injected dose of $(50 \mathrm{mg}$ $/ \mathrm{kg}$ b.wt) of streptozotocin (STZ) (sigma Chemical co.) freshly dissolved in citrate buffer, PH 4.5. Control rats were received an equivalent volume of vehicle (citrate buffer) alone. Two days later, STZ- treated rats were fasted for 12 hours, and blood samples were collected from the orbital venous sinus for glucose determination. Rats in diabetic group with blood glucose levels higher than 250 $\mathrm{mg} / \mathrm{dl}$ were considered diabetic and included for further studies (Ramanathan et al., 1999). The animals were allowed to drink glucose solution $(5 \% \quad \mathrm{w} / \mathrm{v})$ overnight to avoid hypoglycemia which might be induced by streptozotocin (STZ).

\section{Animal Grouping:}

After two days of diabetes induction indicating development of diabetes all rats were divided into four main equal groups, 15 rats each, placed in individual cages and classified as follow:

Group 1: (control group): consists of 15 rats received no drugs, serve as control for all experimental groups.

Group 2: (Diabetic non-treated group): consists of 15 rats received no drugs, serve as STZ induced diabetic groups.

Group 3: (Diabetic nano-curcumin treated group): consists of 15 rats, received curcumin nanoparticle at a dose level of $2 \mathrm{mg} / \mathrm{kg}$ b.wt /day orally. (Suryanarayana et al., 2005).

Group 4: (Diabetic Curcumin Copper Oxide Nano Composite treated group): consists of 15 rats, received oral daily dose of $(7 \mathrm{mg} / \mathrm{kg}$ b.wt) Curcumin Copper Oxide Nano Composite (Zhang et al., 2017).

\subsection{Sampling:}

Blood samples:

Blood samples were collected from retroorbital plexus of eyes in clean dry screwcapped tubes, then allowed to coagulate at room temperature for 30 minutes and centrifuged at 3000 r. p. m. for 15 minutes.
The clean, clear-serum was aspirated by Pasteur pipette and received in a dry sterile sample tube, processed directly for glucose determination and then kept in a deep freeze at $-20^{\circ} \mathrm{C}$ until used for subsequent biochemical analysis.

All sera were analyzed for the following parameters:

L-Malondialehyde (L-MDA), Superoxide dismutase (SOD) and Reduced Glutathione (GSH).

Tissue samples (pancreas and liver):

After finishing blood samples, rats of each group were sacrificed using highly sterilized scissors $\left(180^{\circ} \mathrm{C}\right.$ for 6 hours) to avoid RNA degradation by RNases and latex gloves wearied to minimize RNase contamination. The abdomen was opened and the (pancreas and liver) samples were directly excised and it was wrapped in aluminum foil and put immediately in liquid nitrogen container to make snap-freezing of tissue and minimize the action of endogenous RNase, which used for RT-PCR analysis. Pancreatic samples were used for measuring insulin concentration and Liver samples were used for determination of gene expression of insulin receptor substrate 2 and insulin receptor-A.

\subsection{Biochemical Analysis:}

Serum glucose, L-MDA, GSH and SOD were determined according to the methods described by Trinder, (1969), Mesbah et al., (2004), Moron et al., (1979) and Kakkar et al., (1984) respectively. Insulin concentration in pancreatic tissue was determined by using Enzyme Linked Immunosorbent Assay kit according to Judzewitsch et al., (1982). Moreover, the mRNA expression levels of IRA and IRs- 2 were determined by Real time quantitative polymerase chain reaction (Real time PCR) analysis in liver of rats. $(\mathrm{Ct})$ of housekeeping target gene were normalized with quantities gene ( $\beta$-actin) by used the 2$\Delta \Delta \mathrm{Ct}$ method (Livak and Schmittgen, 2001). 


\subsection{Statistical Analysis:}

The obtained data were analyzed and graphically represented using the statistical package for social science (SPSS/11 software (2012). for obtaining mean and standard deviation and error. The data were analyzed using one-way ANOVA to determine the statistical significance of differences among groups when $p<0.05$. Duncan's test was used for making multiple comparisons among the groups for testing the inter-grouping homogeneity (Snedecor and Cochran, 1969).

\section{RESULTS and DISCUSSION}

In this study, rats injected with STZ showed a significant increase in serum glucose concentration compared $(p<0.05)$ to control group and significant decrease with curcumin and curcumin copper oxide nanocomposite administration compared to STZ- induced diabetic rats according to the recorded data in (Table 1). These results are nearly similar to those reported by (Sayyed et al., 2006) who mentioned that, STZ- induced diabetic rats showed approximately five - fold increase in the blood glucose levels after STZ administration. Also, (Kuhad and Chopra, 2009) reported that, injected mice with STZ had significantly higher blood glucose level than non-diabetic rats.

Treatment with curcumin nanoparticles and its combination with copper oxide nanoparticle to form curcmin copper oxide nanocomposite reduced elevated blood glucose level in streptozotocin induced diabetic rats when compared to normal group. These results are almost similar to those recorded by Chuengsamarn et al., (2012) who mentioned that curcumin is effective in reducing glycemia and hyperlipidemia in rodent models and is relatively inexpensive and safe.

The obtained data demonstrated in (Table 1) showed a significant increase in serum MDA concentration in STZ-induced diabetic rats when compared with control group.

These results are nearly similar to those reported by (Kailash, 2000) who showed that, the diabetic rats had higher serum MDA than the normal rats. However increased lipid peroxidations have been observed in STZinduced diabetic rats and in patients with diabetes. This could be due to increased levels of reactive oxygen species (ROS) (Kailsh, 2000). Moreover, Malonadialdehyde (MDA) is generated in vivo by peroxidation of polyunsaturated fatty acids and represent a stable end product of lipid peroxidation. It is an extensively studied biomarker of lipid peroxidation MDA is typically quantified from various blood compartments (plasma, serum, lymphocytes) and tissue using a colorimetric assay based on the reaction between MDA and thiobarbituric acid (TBARS) (Shah et al., 2014).

On the other hand, lipid peroxidation may bring about protein damage and inactivation of membrane-bound enzymes either through direct attack of free radicals or by chemical modifications of its end products, such as MDA (Coskun et al., 2005 and El-Missiry and Gindy , 2000).

Administration of nanocurcumin and curcumin copper oxide nanoparticles in STZinduced diabetic rats resulted in a significant decrease in MDA level compared to STZ control group. These results go in hand with those of Mrudula et al., (2007) who reported that curcumin decrease lipid peroxidation and serum MDA levels. In another study Curcumin, the principal constituent of turmeric has a unique conjugated structure, which includes two methoxylated phenols and an enol form of b-diketone, processes typical radical-trapping ability as a chain-breaking antioxidant thereby prevents MDA generation (Masuda and Maekawa, 2001). 
The Presented findings showed that, administration of nanocurcumin and curcumin copper oxide nanoparticles to STZ-induced diabetic rats resulted in a significant increase in GSH level compared to STZ control group. Although the best results in GSH level by treating with curcumin copper oxide nanoparticles compared to that of nanocurcumin. Similarly, Al-Omar et al., (2006) who reported that, curcumin increased the levels of GSH in diabetic rats. Also, Murgan and Pari (2006) showed that, curcumin and its metabolite tetrahydrocurcumin decreased modulation of oxidative stress through increasing GSH and reduction in lipids and lipids peroxidation.

Oxidative stress is a state of imbalance between generation of reactive oxygen species and the levels of antioxidant defense system. Antioxidants constitute the foremost defense system that limit the toxicity associated with free radicals. It is known that under physiological conditions, oxy radicals are part of normal regulatory circuits and cellular redox state is very much sensitive to antioxidants. However, increase in influx of oxy radicals and loss of cellular redox homeostasis can cause oxidative stress (Barja, 2000). On the other hand, the recorded data showed the cellular levels of SOD were significantly turned down in the diabetic group as compared with the control group. Therefore, compared with the diabetic control group, diabetic treated group, treated with curcumin nanoparticles showed a significant increase in SOD concentration and the best results were that of the group treated with curcumin copper oxide nanoparticles and these results nearly agree with Tisato et al. (2010) who mentioned that Copper is an integral part of the antioxidant enzyme, copper-zinc superoxide dismutase $(\mathrm{Cu}, \mathrm{Zn}$ SOD). Also, the recorded data showed that, a significant decrease in insulin concentration was observed in streptozotocin-induced diabetic rats all over the period of the experiments. The obtained data showed that, curcumin nanoparticles and curcumin copper oxide nanocomposite could increase insulin concentration and these results agree with (Meghana et al., 2007) who stated that curcumin increased islet viability and delayed islet ROS production.

Curcumin also can elevate plasma insulin level and increase lipoprotein lipase (LPL) activity (Seo et al., 2008). Curcumin treatment increased the number of small pancreatic islets and decreased lymphocyte infiltration in pancreatic islets (Chanpoo et al., 2010). Inclusion of curcumin in bone marrow transplantation increased islet regeneration and insulin secretion (El-Azab et al., 2011).

In addition to these results, the obtained data pointed out that, mRNA expression level of insulin gene IR-A and IR-2 appeared to upregulated in curcumin nanoparticles and Curcumin copper oxide nanoparticles treated groups as compared with the diabetic nontreated group.

Moreover, insulin directly influences the concentration of its own receptors has been confirmed both in vitro and in vivo by (Kobayashi et al., 1978). This cycle of lower receptor concentration with higher insulin concentrations can be explained by a decrease in affinity of the insulin hormone for its receptor (Kahn, 1994). Also, in a study by (Bathena et al., 1986), rats fed a high-fat diet developed insulin resistance due to lower insulin receptor numbers and binding affinity, which were then restored to normal with a standard diet. Insulin receptor substrate molecules are key mediators in insulin signaling and play a central role in maintaining basic cellular functions such as growth, survival and metabolism. They act as docking proteins between the insulin receptor and a complex network of intracellular 
signaling molecules. Four members (IRS-1, IRS-2, IRS-3, IRS-4) of this family have been identified that differ as to tissue distribution, sub cellular localization, developmental expression, binding to the insulin receptor, and interaction with $\mathrm{SH} 2$ domain containing proteins. (Aytug et al., 2003).

The role of IRS molecules are mediators of insulin signaling through the insulin receptor is firmly established (White, 1998). It is less clear whether different IRS molecules play redundant or selective roles in insulin action in different tissues (Yamauchi et al., 1996).

\section{Conclusion}

Form the obtained results it could be concluded that, the experimental induction of diabetes in male rats resulted in significant increase in the level of blood glucose, serum L-malondialdehyde. Meanwhile, significant decrease in pancreatic insulin level and serum GSH and SOD in addition to a significant downregulation in hepatic insulin receptor A (IR-A) and hepatic insulin receptor substrate2 (IRS-2) mRNA gene levels of STZ-induced diabetic rats were observed all over the period of the experiment. The treatment of diabetic rats with nanoparticles curcumin and curcumin-copper oxide nanocomposite plays an important role in the distribution and consumption of blood glucose level in diabetic rats by improving and raising the efficiency of the pancreatic cells to increase the secretion of the insulin hormone and also reduce insulin resistance through activation of gene expression responsible for the insulin receptors. Therefore, we recommended that, administration of curcumin nanoparticles and curcumin-copper oxide nanocomposite in diabetic patients are very essential to attenuate diabetic complications.

Table 1: Effect of curcumin CuO NPs on the serum glucose concentration, MDA, GSH and SOD in STZ-induced diabetic rats.

\begin{tabular}{|c|c|c|c|c|c|c|c|c|}
\hline \multirow{2}{*}{$\begin{array}{l}\text { Parameter } \\
\text { Groups }\end{array}$} & \multicolumn{2}{|c|}{$\begin{array}{c}\text { Serum Glucose } \\
\text { Concentration } \\
(\mathrm{mg} / \mathrm{dl})\end{array}$} & \multicolumn{2}{|c|}{ MDA (nM/ml) } & \multicolumn{2}{|c|}{ GSH (IU/ml) } & \multicolumn{2}{|c|}{ SOD (IU/ml) } \\
\hline & 2 Weeks & 4 Weeks & 2 Weeks & 4 Weeks & 2 Weeks & 4 Weeks & 2 Weeks & 4 Weeks \\
\hline G1 (control normal) & $\begin{array}{c}113.67 \pm 4 . \\
06^{\mathrm{d}}\end{array}$ & $\begin{array}{c}67.67 \pm 7.4 \\
5^{\mathrm{d}}\end{array}$ & $\begin{array}{l}35.00 \pm 0 . \\
58^{\mathrm{d}}\end{array}$ & $\begin{array}{c}34.33 \pm 2 . \\
03^{\mathrm{d}}\end{array}$ & $\begin{array}{c}30.43 \pm 0 . \\
81^{\mathrm{a}}\end{array}$ & $\begin{array}{c}34.07 \pm 1 \\
18^{\mathrm{a}}\end{array}$ & $\begin{array}{c}16.70 \pm 0 . \\
44^{\mathrm{a}}\end{array}$ & $\begin{array}{c}17.03 \pm 0 . \\
55^{\mathrm{a}}\end{array}$ \\
\hline G2 (STZ) & $\begin{array}{c}500.67 \pm 6 . \\
57^{\mathrm{a}}\end{array}$ & $\begin{array}{c}511.67 \pm 14 \\
.40^{\mathrm{a}}\end{array}$ & $\begin{array}{c}75.80 \pm 1 \\
47^{\mathrm{a}}\end{array}$ & $\begin{array}{c}64.13 \pm 2 . \\
31^{\mathrm{a}}\end{array}$ & $\begin{array}{c}7.27 \pm 0.3 \\
7^{\mathrm{d}}\end{array}$ & $\begin{array}{c}10.08 \pm 1 \\
12^{\mathrm{d}}\end{array}$ & $\begin{array}{c}5.57 \pm 0.5 \\
0^{\mathrm{d}}\end{array}$ & $\begin{array}{c}6.47 \pm 0.5 \\
7^{\mathrm{d}}\end{array}$ \\
\hline $\begin{array}{l}\text { G3 (STZ + curcumin } \\
\text { NPs) }\end{array}$ & $\begin{array}{c}328.67 \pm 10 \\
.73^{\mathrm{b}}\end{array}$ & $\begin{array}{c}260.33 \pm 13 \\
.30 \mathrm{~b}\end{array}$ & $\begin{array}{c}55.00 \pm 2 . \\
08^{\mathrm{b}}\end{array}$ & $\begin{array}{c}49.80 \pm 3 \\
21^{\mathrm{b}}\end{array}$ & $\begin{array}{c}15.30 \pm 0 . \\
72^{\mathrm{c}}\end{array}$ & $\begin{array}{c}18.58^{ \pm} 1 \\
09^{c}\end{array}$ & $\begin{array}{c}8.70 \pm 0.4 \\
2^{\mathrm{c}}\end{array}$ & $\begin{array}{c}10.93 \pm 1 . \\
35^{\mathrm{c}}\end{array}$ \\
\hline $\begin{array}{l}\text { G4 (STZ + curcumin } \\
\text { CuO NPs) }\end{array}$ & $\begin{array}{c}277.00 \pm 12 \\
.50^{\mathrm{c}}\end{array}$ & $\begin{array}{c}199.00 \pm 13 \\
.20^{\mathrm{c}}\end{array}$ & $\begin{array}{c}45.40 \pm 0 . \\
83^{\mathrm{c}}\end{array}$ & $\begin{array}{c}40.83 \pm 1 \\
74^{c}\end{array}$ & $\begin{array}{l}22.47 \pm 0 . \\
52^{\mathrm{b}}\end{array}$ & $\begin{array}{c}26.74 \pm 1 . \\
51^{\mathrm{b}}\end{array}$ & $\begin{array}{c}12.10 \pm 0 . \\
32^{\mathrm{b}}\end{array}$ & $\begin{array}{l}14.51 \pm 0 . \\
87^{\mathrm{b}, \mathrm{c}}\end{array}$ \\
\hline
\end{tabular}

STZ-induced diabetic rats. Data are presented as (Mean \pm S.E). $\quad$ S.E $=$ Standard error.

Means within the same column carrying different superscript letters are significantly different $(\mathrm{P} \leq$ $0.05)$. 
Table 2: Effect of curcumin CuO NPs on insulin concentration (nmol/g tissue) in the pancreas, on the relative expression of IRS-2 gene in liver tissues and on the relative expression of IR-A gene in liver tissues of STZ-induced diabetic rats.

\begin{tabular}{lccc}
\hline Parameter & $\begin{array}{l}\text { Insulin } \\
\text { Concentration } \\
\text { in pancreatic tissue } \\
\text { (nmol/g tissue) }\end{array}$ & $\begin{array}{c}\text { Relative expression of } \\
\text { IRS-2 gene in liver } \\
\text { tissues }\end{array}$ & $\begin{array}{c}\text { Relative expression of } \\
\text { IR-A gene in liver } \\
\text { tissues }\end{array}$ \\
\hline Animal Groups & $5.23 \pm 0.43^{\mathrm{a}}$ & $1.00 \pm 0.02^{\mathrm{a}}$ & $1.00 \pm 0.02^{\mathrm{a}}$ \\
G1 (control normal) & $1.00 \pm 0.12^{\mathrm{d}}$ & $0.04 \pm 0.01^{\mathrm{d}}$ & $0.01 \pm 0.002^{\mathrm{d}}$ \\
$\mathrm{G} 2$ (STZ) & $2.33 \pm 0.15^{\mathrm{c}}$ & $0.24 \pm 0.03^{\mathrm{c}}$ & $0.13 \pm 0.02^{\mathrm{c}}$ \\
$\mathrm{G} 3(\mathrm{STZ}+$ curcumin NPs) & $3.70 \pm 0.15^{\mathrm{b}}$ & $0.48 \pm 0.04^{\mathrm{b}}$ & $0.41 \pm 0.03^{\mathrm{b}}$ \\
$\mathrm{G} 4(\mathrm{STZ}+$ curcumin CuO NPs) & & & \\
\hline
\end{tabular}

\section{REFERENCES}

Al-Omar, F.A.; Abdulgadir, M.M.; Al joni, K.S.and Al Majed, A.A. (2006): Immediate and delayed treatments with curcumin prevents forbrain ischemiainduced neuronal damages and with oxidative insult in the rat hippocampus. Neurochem Res. 31:611-618.

American Diabetes Association (ADA) (2018): Standards of Medical Care in Diabetes. 41, 1.

Aytug H., Khouja, M., and Vergara, F. E. (2003): Use of Genetic Algorithems to Solve Production and Operations Management Problems: a. Int. J. Prod. Res. 41: 17.

Bathena,S.J., Berlin, E., Revett, $\mathrm{K}$ and Omrnaya, A.E.K. (1986): Modulation of erythrocyte insulin receptors by dietary lipids. Ann. N.Y. Acad. Sci. 463:165-67.

Barja G. (2000): the flux of free radical attack through mitochondrial DNA is related to aging rate. Aging (Milano). 12:342355.

Chanpoo M., Petchpiboonthai H., Panyarachun B., and Anupunpisit V. (2010): "Effect of curcumin in the amelioration of pancreatic islets in streptozotocin-induced diabetic mice,"
Journal of the Medical Association of Thailand $=$ ChotmaihetThangphaet, 152-159.

Chuengsamarn S., Rattanamongkolgul S., Luechapudiporn R., Phisalaphong C., and Jirawatnotai S. (2012): "Curcumin extract for prevention of type 2 diabetes," Diabetes Care, 2121-2127.

Coskun, O.; Kanter, M.; Korkmaz, A. and oter, S. (2005): Quercetin, a flavonoid antioxidant, prevents and protects streptozotocin-induced oxidative stress and bête-cell damage in rat pancreas. Pharmacol res 51:117-123.

El-Azab M. F., Attia F. M., and El-Mowafy A. M. (2011): "Novel role of curcumin combined with bone marrow transplantation in reversing experimental diabetes: effects on pancreatic islet regeneration, oxidative stress, and inflammatory cytokines," European Journal of Pharmacology, 41-48.

El-Missiry, M. and El Gindy, A. (2000): Amelioration of alloxan induced diabetes mellitus and oxidative stress in rats by oil of Eruca sativa seeds. Ann NutrMetab 44:97-100.

El-Sherif Ahmed A. J. (2012): Solution Chem., 41: 1522-1554. 
Javed R, Ahmed M, Haq ul, Nisa I, Zia S, M. (2017): PVP and PEG doped $\mathrm{CuO}$ nanoparticles are more biologically active: antibacterial, antioxidant, antidiabetic and cytotoxic perspective. Mat Sci Eng C 79:108-115.

Joseph J., G.Boomadevi Janaki. (2014): Synthesis, Structural characterization and biological studies of copper complexes with -aminobenzothiazole deravatives Sci. 5:693-704.

Judzewitsch, R.G., Pfeifer, M.A., Best, J.D., Beard, J.C., Halter, J.B. and Porte, D.J. (1982): Chronic chlorpropamide therapy of non-insulin-dependent diabetes augments basal and stimulated insulin secretion by increasing islet sensitivity to glucose.J. Clin. End. And Metab., 55(2): 321-328.

Kahn, C.R. (1994): Insulin action, diabetogenes, and the cause of type II diabetes. Diabetes 43: 1066-84.

Kailash, P. (2000): Oxidative stressas a mechanism of diabetes in diabetic BB prone rats: Effect of secoisolariciresinol diglucoside. Molecular and Cellular Biochemistry.209:89-96.

Kakkar P., Das, B., Viswanathan, P.N. (1984): A modified spectrophotometric assay of superoxide dismutase. Indian J.Biochem Biophys, 21: 130-132.

Kobayashi, M. and Olefsky, J.M. (1978): Effect of experimental hyperinsuiinoma on insulin binding and glucose transport in isolated rat adipocytes. Am. J. Physiol. 235: E53E62.

Kuhad, A. and Chopra K. (2009): Attenuation of diabetic nephropathy by tocotrienol: involvement of NFKB signaling pathway. Life Sci. 84:296-301.

Livak KJ, Schmittgen TD. (2001): Analysis of relative gene expression data using real time quantitative $\mathrm{PCR}$ and the $2 \Delta \Delta \mathrm{C}(\mathrm{T})$ Method. Methods 25(4):
402-408.

Masuda, T. and Maekawa, T. (2001): Chemical studies on antioxidant mechanisms of curcumin: analysis of oxidative coupling products from curcumin and lionleate. J Agric Food Chem. 49:2539-2547.

Meghana K., Sanjeev G., and Ramesh B. (2007): "Curcumin prevents streptozotocin-induced islet damage by scavenging free radicals: a prophylactic and protective role," European Journal of Pharmacology, 183-191.

Mesbah L., Soraya B., Narimane S., Jean P.F. (2004): protective effect of flavonides against the toxicity of vinblastine cyclophosphamide and paracetamol by inhibition of lipid peroxidation and increase of liver glutathione. Haematol. 7 (1): 59-67.

Moron M.S., Depierre J.W., Mannervik B. (1979): Levels of glutathione, glutathione reductase and glutathioneS-transferase activities in rat lung and liver; Biochem. Biophys Acta; 582; 6778.

Mrudula, T.; Suryanarayana, P.; and Reddy, G.B. (2007): Effect of curcumin on hyperglycemia-induced vascular endothelial growth factor expression in streptozotocin-induced diabetic rat retina. Biochem Biophys Res Commun.361:528-532.

Murgan, P. and Pari L. (2006): Effect of tetrahydrocurcumin on lipid peroxidation and lipids in streptozotocin-nicotinamide-induced diabetic rats. Basic Clinpharmacol Toxicol. 99:122-127.

Piyasi Mukhopadhyaya, Subhajit Maityc, Sudipto Mandale, Abhay Sankar Chakrabortic, A.K. Prajapatia, P.P. Kundub (2017): Preparation, characterization and in vivo evaluation of $\mathrm{pH}$ sensitive, safe quercetinsuccinylated chitosan-alginate coreshell-corona nanoparticle for diabetes 
treatment,182:42-51.

Ramanathan, M., Jaiswal, A.K., and Bhattacharya S.K. (1999): Superoxide dismutase, catalase and glutathione peroxidase activities in the brain of streptozocine induced diabetic rats. Ind. J. Exp. Biol., 37: 182-183.

Sayyed, S.G.; Kumar, A. And Sharma, S.S. (2006): Effects of US3836E on nerve functions, hypcralgesia and nxidative stress in experimental diabetic neuropathy. Life Sci 79: 777-783.

Seo K.-I., Choi M.-S., Jung U. J. (2008): "Effect of curcumin supplementation on blood glucose, plasma insulin, and glucose homeostasis related enzyme activities in diabetic $\mathrm{db} / \mathrm{db}$ mice," Molecular Nutrition and Food Research, 995- 1004.

Shah, D.; Mahajan, N.; Sah, S.; Nath, S. K and Paudyal, B. (2014): Oxidative stress and its biomarkers in systemic lupus erythematosus ' Journal of Biomedical science, 21:2.

Snedecor and Cochran, (1969): Statistical methods, the IOWA state unive. Press, Ames, IOWA, U.S.A, 593.

Suryanarayana P, Saraswat M, Mrudula T, Krishna TP, Krishnaswamy K. (2005): Curcumin and turmeric delay streptozotocin induced diabetic cataract in rats, 46:2092-2099.

Tisato F., Marzano C., Porchia M., Pellei M., Santini C. (2010): Med Res Reviews, 30: 708.

Trinder, P. (1969): An. Clin. Biochem. 6:24.

White, M.F. (1998): The IRS-signaling system: A network of docking proteins that mediate insulin and interleukin signaling. MolCell Biochem.182:3-11.

Yamauchi, T., Tobe, K., Tamemoto, H., Ueki, K., Kaburagi, Y., Yamamoto-Honda, R., Takahashi, Y., Yoshizawa, F., Aizawa, S., Akanuma, Y., Sonenberg, N., Yazaki, Y., and Kadowaki, T.
(1996): Insulin signaling and insulin actions in the muscles and livers of insulin-resistance, insulin receptor substrate 1- deficient mice. Mol Cell Biol 16:3074-3084.

Zhang H., Wu X., Mehmood K., Chang Z., Li K., Jiang X., Nabi F., Ijaz M., Rehman MU., Javed MT., Zhou D. (2017): Intestinal epithelial cell injury by copper containing nanoparticles in piglets, 56:151-156.

Rosmini, R. and Simoni, P. (1979): Histological and ultrastructural features of hepatic coccidiosis in rabbits. Revista di Coniglicolture 16: 31-36.

Singla, L.D., Juyal, P.D. and Sandhu, B.S. (2000): Pathology and therapy in naturally Eimeria stiedae - infected rabbits. J. Protozool . Res. 10, 185191.

Southern, L.L. and Baker, D.H. (1983): Eimeria acervulina infection and the zinc-copper interrelationship in the chick. Poult Sci.; 62(2):401-4.

Wang ,J.S. and Tsai, S.F. (1991): Prevalence and pathological study on rabbit hepatic coccidiosis in Taiwan. Department of Veterinary Medicine, National Chung- Hsing University, Taichung, Taiwan, Republic of China. Proc Natl Sci Counc Repub China B. ; 15(4):240-3. 